\title{
Balloon-expandable covered stent implantation for treatment of traumatic aortic pseudoaneurysm in a pediatric patient
}

\author{
M. Elisabeth Heal, DO, Shahryar M. Chowdhury, MD, and Varsha M. Bandisode, MD, Charleston, SC
}

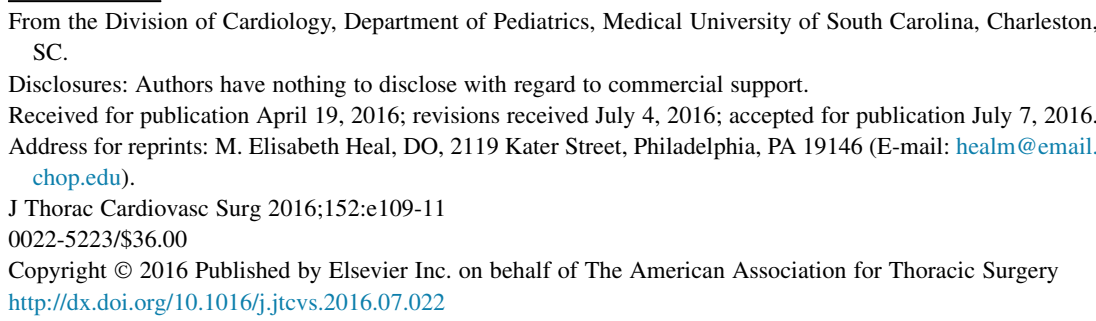

From the Division of Cardiology, Department of Pediatrics, Medical University of South Carolina, Charleston, SC.

Disclosures: Authors have nothing to disclose with regard to commercial support.

Received for publication April 19, 2016; revisions received July 4, 2016; accepted for publication July 7, 2016 Address for reprints: M. Elisabeth Heal, DO, 2119 Kater Street, Philadelphia, PA 19146 (E-mail: healm@email. chop.edu).

J Thorac Cardiovasc Surg 2016;152:e109-11

$0022-5223 / \$ 36.00$

Copyright (C) 2016 Published by Elsevier Inc. on behalf of The American Association for Thoracic Surgery

http://dx.doi.org/10.1016/j.jtcvs.2016.07.022

Traumatic aortic injury is rare in the pediatric population. Open surgical repair is currently the standard of care, although endovascular techniques are being investigated. $^{1-4}$ In adults, this type of injury is frequently treated percutaneously with self-expanding endograft placement. ${ }^{1,5-7}$ This approach has multiple technical limitations in pediatric patients, specifically the large entry profile of endografts and the inability to adjust the graft diameter with patient somatic growth. ${ }^{2-4}$ Balloonexpandable covered stents offer a treatment alternative better suited to pediatric patients. There is not currently a large diameter, balloon-expandable, covered endovascular stent approved by the Food and Drug Administration for use in the United States; however, the NuMED Covered CP Stent (NuMED, Inc, Hopkinton, NY), a covered Cheatham platinum balloon-expandable stent, is available to centers participating in the Coarctation of the Aorta Stent Trial and the Pulmonary Artery Repair With Covered Stents trial. ${ }^{1,8,9}$ Our case report discusses the youngest patient reported to have undergone successful covered stent implantation for aortic pseudoaneurysm.

\section{CLINICAL SUMMARY}

We present the case of an 8-year-old girl who had been a restrained, rear-seat passenger in a motor vehicle collision. Her head imaging was significant for a small hemorrhagic contusion and a small subdural hematoma. A computed tomographic scan of her chest, abdomen, and pelvis demonstrated an aortic pseudoaneurysm with associated posterior mediastinal hematoma, multiple areas of pulmonary contusion, a single rib fracture, and no visceral injury. The patient was subsequently admitted to the pediatric intensive care unit, where she received a loading dose of fosphenytoin sodium (INN fosphenytoin) for suspected seizure activity and a labetalol hydrochloride (INN labetalol) infusion was begun for blood pressure control. She was transferred to our institution for further evaluation and management.

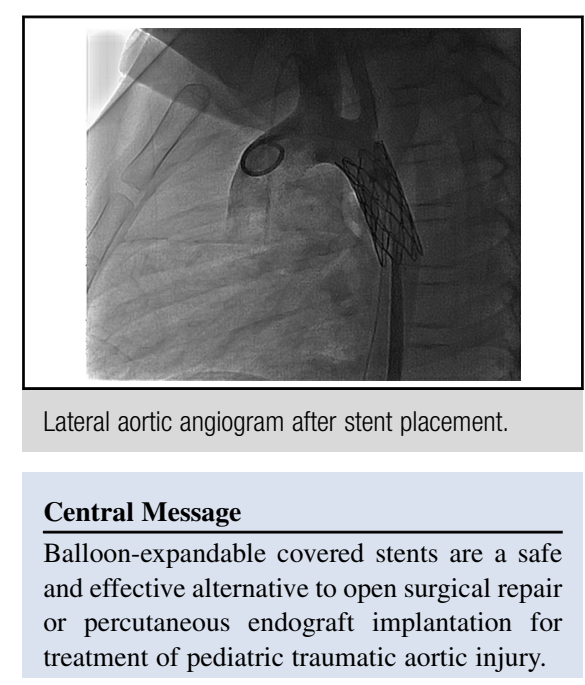

See Editorial Commentary page e113.

A follow-up gated chest computed tomographic angiogram was performed for better visualization of the extent of the aortic injury. Computed tomography demonstrated a focal defect of the anterior aspect of the descending aorta, originating at the isthmus, with an associated pseudoaneurysm. The intimal disruption measured $10.1 \times 6.5 \mathrm{~mm}$, and the aorta distal to the disruption measured $13.1 \times 12.6 \mathrm{~mm}$. The pseudoaneurysm and mediastinal hematoma were both stable in size relative to the study performed in the trauma emergency department.

Because of the presence of intracerebral hemorrhage, the patient was deemed at high risk for systemic anticoagulation required for an operative aortic repair. Available percutaneous endograft sizes were deemed too large for her descending aortic diameter, and the associated risk of vessel injury with the large sheath required to implant the endograft removed this option from consideration. The decision was made to attempt percutaneous covered stent placement across the pseudoaneurysm in the pediatric cardiac catheterization laboratory.

As a participant in the multicenter Pulmonary Artery Repair With Covered Stents trial, our institution has access to NuMED CP balloon-expandable covered stents. In the catheterization laboratory, femoral arterial and venous access were obtained. A pigtail catheter was advanced from the femoral artery retrograde into the transverse aorta, and an angiogram was performed. On the basis of descending aortic measurements, a 14-mm $\times 4-\mathrm{cm}$ 


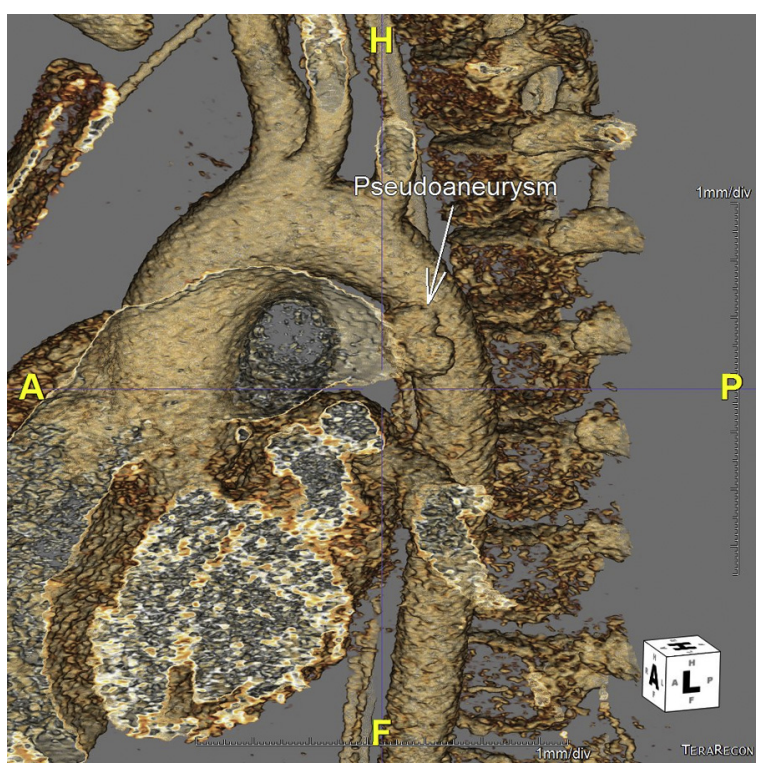

FIGURE 1. Sagittal plane computed tomographic angiogram demonstrating aneurysm formation (arrow) at the anterior aspect of the proximal descending aorta.

covered stent was prepared for use. A Judkins right coronary catheter was advanced into the femoral artery and exchanged for a transseptal sheath. A NuMED BIB (balloon in balloon) angioplasty catheter with the mounted covered stent was advanced through the transseptal sheath to the level of the pseudoaneurysm. The stent was expanded in place. A pigtail catheter was placed into the ascending aorta, and an angiogram was performed, which indicated good wall apposition at the level of the pseudoaneurysm and descending aorta. There was a gap in wall

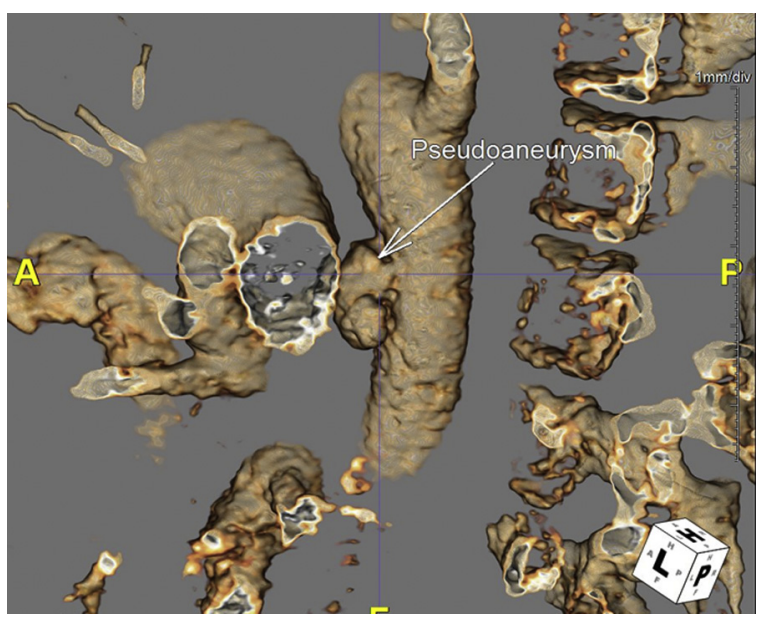

FIGURE 2. Computed tomographic angiogram demonstrating the discrete neck of aneurysm (arrow) in the anterior portion of the descending aorta.

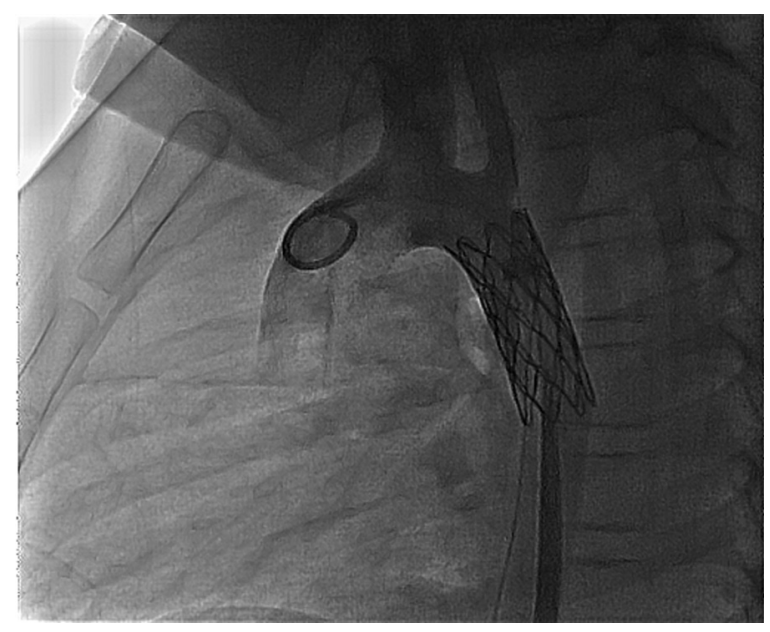

FIGURE 3. Lateral aortic angiogram after stent placement.

apposition as a result of the proximal aortic contour. The pigtail catheter was exchanged for a Coda balloon catheter (Cook Medical Inc, Bloomington, Ind) which was inflated to mold the proximal end of the stent gently to the aortic arch curvature. The Coda balloon catheter was exchanged for the pigtail catheter, and a final angiogram was performed. There was no residual aneurysmal filling, and comparison pressures demonstrated no significant gradient from ascending to descending aorta. The patient was transferred in stable condition to the pediatric intensive care unit for further management. Her postcatheterization course was uneventful, and she was discharged home approximately 1 week after the procedure. She was doing very well at her 1-month follow-up visit, and her echocardiogram demonstrated stable stent position without aortic obstruction. We will continue to follow up with serial echocardiograms, initially at 6-month intervals. The covered stent allows expansion to a maximum diameter of $24 \mathrm{~mm}$ and so may be redilated to match future aortic growth.

\section{DISCUSSION}

Although pediatric traumatic aortic injury is rare, it presents particularly difficult treatment decisions. Open surgical repair remains the standard of care; however, many patients who have sustained aortic injury have concomitant injuries precluding a safe operative procedure. With extensive aortic wall injury, surgical options are limited to interposition graft placement, which would require serial replacement with somatic and aortic growth.

Endovascular endograft placement is a widely used technique in the adult population and has been used in a smaller number of pediatric patients. The endograft 
delivery system is large. Patients with small femoral arteries require surgical exposure of the iliac artery before implantation. The endografts are self-expanding, without adjustable diameter; endografts placed in children therefore serve as a bridge to a later definitive surgical repair. ${ }^{3}$

Balloon-expandable covered NuMED CP stents are delivered through a $14 \mathrm{~F}$ sheath, allowing implantation in a child as small as $20 \mathrm{~kg} .{ }^{10}$ Additional advantages to treatment with covered stents include the ability to redilate to match future aortic growth, avoidance of surgical repair, and shorter recovery time. Disadvantages of covered stent implantation include an increased risk of aortic rupture with balloon expansion as well as the lack of long-term outcome data.

The multicenter Coarctation of the Aorta Stent Trial has demonstrated good short-term outcomes of balloonexpandable covered stent implantation in 6 pediatric patients sustaining traumatic aortic injury. The median age of the trial participants was 13.5 years, with a range of 11 to 14 years. ${ }^{1}$ Long-term results are required to confirm the safety and efficacy of this treatment approach.

\section{CONCLUSIONS}

Percutaneous implantation of balloon-expandable covered stents may be a safe and effective alternative to open surgical repair or percutaneous endograft implantation for treatment of traumatic aortic injury in pediatric patients.

\section{References}

1. Goldstein BH, Hirsch R, Zussman ME, Vincent JA, Torres AJ, Coulson J, Ringel RE, Beekman RH. Percutaneous balloon-expandable covered stent implantation for treatment of traumatic aortic injury in children and adolescents. Am J Cardiol. 2012;110:1541-5.

2. Menini Stahlschmidt CM, Von Bahten LC, Leal Nicoluzzi JE, Corvello A, Stahlschmidt FL, Guimaraes F. Successful endovascular management of a traumatic aortic rupture in a pediatric patient: case report and literature review. Ulus Travma Acil Cerrahi Derg. 2010;16:84-6.

3. Martin MA, Barnatan M, Cole F, Long W, Hill J, Karmy-Jones R. A case report of traumatic aortic rupture in a pediatric patient: a possible role for endovascular management as a bridge to definitive repair. J Trauma. 2009; 67:E136-9.

4. Gunabushanam V, Mishra N, Calderin J, Glick R, Rosca M, Krishnasastry K. Endovascular stenting of blunt thoracic aortic injury in an 11-year-old. J Pediatr Surg. 2010;45:E15-8.

5. Rahimi SA, Darling RC III, Mehta M, Roddy SP, Taggert JB, Sternbach Y. Endovascular repair of thoracic aortic traumatic transections is a safe method in patients with complicated injuries. J Vasc Surg. 2010; 52:891-6.

6. Neschis DG, Moaine S, Gutta R, Charles K, Scalea TM, Flinn WR, et al. Twenty consecutive cases of endograft repair of traumatic aortic disruption: lessons learned. J Vasc Surg. 2007;45:487-92.

7. Amabile P, Collart F, Gariboldi V, Rollet G, Bartoli JM, Piquet P. Surgical versus endovascular treatment of traumatic thoracic aortic rupture. J Vasc Surg. 2004; 40:873-9.

8. Tzifa A, Ewert P, Brzezinska-Rajszys G, Peters B, Zubrzycka M, Rosenthal E, et al. Covered Cheatham-platinum stents for aortic coarctation: early and intermediate-term results. J Am Coll Cardiol. 2006;47: 1457-63.

9. Butera G, Heles M, Macdonald ST, Carminati M. Aortic coarctation complicated by wall aneurysm: the role of covered stents. Catheter Cardiovasc Interv. 2011; 78:926-32.

10. Sandgren T, Sonesson B, Ahlgren R, Länne T. The diameter of the common femoral artery in healthy human: influence of sex, age, and body size. $J$ Vasc Surg. 1999;29:503-10. 